\title{
2 Social media in L2 education: exploring on-line collaborative writing in EFL settings
}

\author{
Robert Martínez-Carrasco ${ }^{1}$
}

Abstract

$\mathrm{T}$ his paper presents a classroom experience regarding the use of wikis in L2 collaborative writing settings. Framed in the current post-positivist educational climate in higher education, the adoption of wikis as a Technology-Enhanced Language Learning (TELL) platform complements and enriches the classroom-based interaction of L2 learners. While developing solid L2 writing and self-expression skills, wikis may be said to foster other related core abilities - reading and comprehension, critical thinking, exegetic skills, integration of culture-specific elements in foreign language learning, and use of new technologies, etc. In the process of drafting culture-bound texts, the co-creating students become aware of the weight of cultural elements in their texts in an asynchronous, cross-cultural communication process, and they are able to bridge the cultural divide not only through non-formal, peer-to-peer learning, but also through empowered cross-cultural understanding in a truly emancipating English as a Foreign Language (EFL) setting.

Keywords: collaborative writing, wikis, TELL, digital pedagogy, informal learning.

\section{Introduction}

The way literacy is understood in contemporary settings, following the rapid implementation of ever-changing information and communication

\footnotetext{
1. Jaume I University, Castelló de la Plana, Spain; rcarrasc@uji.es
}

How to cite this chapter: Martínez-Carrasco, R. (2018). Social media in L2 education: exploring on-line collaborative writing in EFL settings. In F. Rosell-Aguilar, T. Beaven, \& M. Fuertes Gutiérrez (Eds), Innovative language teaching and learning at university: integrating informal learning into formal language education (pp. 17-26). Research-publishing.net. https://doi.org/10.14705/rpnet.2018.22.772 
technologies, requires particular awareness of the new types of discourses and social practices that justify the introduction of TELL platforms in the L2 classroom (Chun, Smith, \& Kern, 2016). Indeed, in the socialisation of L2 students, innovative technology-enhanced writing tools - wikis, blogs, Google Docs, etc. - have expanded the range, scope, and possibilities of contemporary collaboration (Yim \& Warschauer, 2017, p. 147), reinforcing the cognitive, post-positivist turn in higher education characterised by situated practices in student-centred environments where procedural knowledge (knowing how) and the integrated mobilisation of clusters of competences seem to be gaining increasing momentum. This approach has undoubtedly allowed students to resort to non-formal and informal activities and platforms to round their learning experience.

Indeed, the introduction of technologies in the classroom may be said to have blurred, in a way, some of the boundaries between formal, informal, and non-formal education. While the literature has explored the three concepts extensively and has suggested many a definition, the educational implications of contemporary digital pedagogy seem to complicate the narrative, suggesting that informal and formal learning are part of a continuum in every technologyenhanced learning situation (Lai, Khaddage, \& Knezek, 2013). Instead, it is the intention and the structure of the learning experience that characterises the debate, since most technologically enhanced pedagogical approaches reflect varying degrees of formality and informality simultaneously, and therefore they both have an impact on the learning experience of students.

Wikis, as Elola and Oskoz (2010) argue, "provide learners with a tool to create, transform, and erase their work with built-in accountability" (p. 53), which affects the motivation of students and triggers a significant number of valuable skills, namely content mastery, self-confidence, autonomy, and group work, among others. At the same time, wikis may serve as a platform for cross-cultural awareness and communication, reflecting on the power relations that shape the meaning negotiation processes following the interaction of two socio-cultural communities. 


\section{Introducing Wikipedia in the L2 classroom}

"As a ground-breaking and interdisciplinary phenomenon", Alonso (2015, p. 90) argues, Wikipedia has attracted the attention of researchers from many fields, including communication, politics, and language. Indeed, Wikipedia has become, for many, a platform to situate their teaching practices and unfold a plethora of activities that may suit the most varied fields, specifically in the L2 classroom: critical analysis of articles, article correction and revision, article creation, article expansion and improvement, and translation of articles, etc. (Lerga \& Aibar, 2015).

Wikimedia Foundation is well aware of the possibilities Wikipedia offers to the post-positivist classroom, and indeed a number of its affiliates have implemented several educational projects, be it through the many specific sections within the online encyclopaedia where resources and educational content are brought together (Lerga \& Aibar, 2015, p. 3) or through Wikiprojects, that is, teams of users working for a common objective. Besides, the Wikimedia Educational Portal, a wiki aimed at coordinating and spreading educational activities and projects across the world, was created for anyone interested in using Wikipedia for educational purposes (Lerga \& Aibar, 2015, p. 4), linking global projects, spreading new initiatives and resources, etc. Launched back in 2010, the portal serves as a coordination meeting point for educators and students with the support, resources, and practical information Wikimedia offers.

\section{The project}

\subsection{Motivation}

The classroom experience below elaborates on those premises and introduces Wikipedia as a platform for collaborative writing and inter-cultural awareness. The participants involved, 13 males and 93 females, were all foreign speakers of English enrolled in the module 'English language for translators and interpreters' 
corresponding to the second year of the degree in Translation and Interpreting offered by Jaume I University (Spain). The overall objective of the course was for students to reach a $\mathrm{C} 1$ level of English according to the Common European Framework of languages (CEFR). Following a holistic methodology, the project sought the progressive, culturally-aware socialisation of students through the introduction of real discursive practices in the L2 classroom, mobilising a substantial number of the so-called 'generic competences' reflected in the Tuning Project (González \& Wagenaar, 2003), a European initiative started in 2000 as a way to link the political objectives of the Bologna Process and the Lisbon Strategy to the higher educational sector and the Common European Framework: emancipation, creativity, motivation, responsibility, empowerment, and autonomy, etc. In this particular case, beside the module-specific competences related to linguistic and discursive proficiency in L2, the wiki-project presented along these pages addressed most of the generic competences (Table 1) included in Muñoz Raya (2004).

Table 1. Generic competences explored throughout wiki-project

\begin{tabular}{|c|c|}
\hline Personal generic competences & Instrumental generic competences \\
\hline \multirow{8}{*}{$\begin{array}{l}\text { - Ethic commitment } \\
\text { - Critical reasoning } \\
\text { - Appreciation of diver- } \\
\text { sity and multiculturality } \\
\text { - Interpersonal skills } \\
\text { - Teamwork } \\
\text { - Leadership }\end{array}$} & - Knowledge of a foreign language \\
\hline & - Planning and time management \\
\hline & - Decision making \\
\hline & - Problem solving \\
\hline & - Capacity for analysis and synthesis \\
\hline & - Use of information and com- \\
\hline & munications technology \\
\hline & - Information management skills \\
\hline Systemic generic competences & Other generic competences \\
\hline - Concern for quality & - Capacity for applying knowl- \\
\hline - Capacity to learn & \\
\hline - Capacity to adapt to new situations & - Ability to work on their own \\
\hline - Creativity & - Project design and management \\
\hline
\end{tabular}




\subsection{Setting up the project}

Students were asked to create, in groups of five members, an expository text aimed at a global audience that reflected part of their cultural background and identity: something related to the festivities and festivals of their hometowns, traditions, or gastronomy, etc. The underlying rationale was twofold: on the one hand, to focus on text production, discursive practices, and language proficiency collaboratively; developing a number of strategies and competences that complement individual work. On the other, to make students aware of the situated nature of both linguistic and cultural practices, since it is when students are faced with the difficulties of conveying culturespecific references in their texts that they reflect on the cultural load inherent to language and culture. Wrongly understood as factual systems, students confront the idea that languages, as semiological systems, condition speakers in the way they apprehend reality around them, and therefore condition their linguistic and cultural practices. Consequently, in order to address text production successfully, students realised that they needed to implement a number of strategies in order to bridge the cultural gap (paraphrases, use of loans, calques, and neologisms, etc.).

Students were told that their text was to be drafted and modified on the wiki space, and therefore all communication among group members or between groups would take place via the wiki. Similarly, students were reminded that the project would take place exclusively outside the classroom as an ongoing group project. No guidelines were given regarding the way to work. Students were allowed to decide how they would address their collaborative writing process: synchronously or asynchronously, dividing the text into sub-sections drafted individually or working together on each and every sub-section, etc. The rationale behind that decision was for the researcher to explore the patterns of collaboration that emerge naturally when students are faced with such collaborative tasks. Focus group interviews in which students were asked to explain why they had opted for a given particular approach were recorded at the end of the project. 
The different changes in the articles were monitored in the history page of the wiki, which made it possible for the lecturer to analyse the evolution of texts and the way students created, edited, and negotiated the relevant content and structure of their text. When it came to group formation, students were told that all members in a group should have a similar level of English, even if it was up to the group to make the decision. Similarly, since students approached text production as a team, they were assessed as a team. Once the first draft of the texts was ready, the texts were distributed among the groups for peer revision and correction. Students were encouraged to revise the texts, looking for areas for improvement in the overall text production process. Before submitting the final draft, students were asked to evaluate the suggestions by their peers, accepting or rejecting them accordingly. In case they did not agree with the corrections, the groups were encouraged to discuss the different options available until a common solution was found, fostering further asynchronous collaboration and interaction. The lecturer assessed the final drafts, thus completing the project.

\section{Methodology and data collection}

The project relies on critical pragmatist grounds, conceiving education as something in constant re-negotiation and interpretation, influenced by power relations within society.

In order to measure and study both the quality of the resulting texts and the impressions of the students, a number of strategies were implemented. On the one hand, focus group interviews where the students reflected on the overall process and their perceptions regarding both collaborative writing and the use of wikis. On the other hand, an analysis of their texts was carried out at two levels. First of all, in order to measure the quality of the texts for classroom purposes, the Writing Assessment Scale by Cambridge English Language Assessment was applied. The rubric, divided in four sub-scales (content, communicative achievement, organisation, and language) helped students understand their actual command of English and the different aspects they should be working on 
for future written assignments. For research purposes, a deeper textual analysis is currently taking place regarding the type of mistakes students make not only when they write collaboratively but also when they are asked to revise the texts drafted by their peers: the level of awareness they display regarding what constitutes a valid/not valid piece of writing and the particular elements they systematically detect or deem more important, etc.

Regarding the focus group interviews, students were asked a number of questions related to collaboration in L2 settings, the use of wikis, and other technologyenhanced elements in the L2 classroom, and their own perceptions of whether such activities are of any use in foreign language education. The results appear to back prior literature regarding the use of wikis in the L2 classroom. Indeed, all focus groups mention systematically four areas of remarkable satisfaction: motivation, deeper and more effective socialisation, greater command of their L2, and the positive impact of peer scaffolding. The following two extracts by two female students in two different groups summarise the general opinion of the participating students regarding the usefulness and their perceptions of the collaborative learning experience:

"To be honest, I hate working in groups. It makes things much more difficult because you need to make sure that all your timetables match. The good thing of wikis is that we didn't have to work online at the same time, so we could see the change history and leave messages for our classmates as we were writing. At the beginning I thought that using a wiki would complicate things unnecessarily, but after a while we all got into it. I mean, this is not the typical essay you are asked to write in an English class. It is a longer project, and we even had to include audio-visual materials, videos and links to other websites and stuff, and that was interesting. I think it was much more interesting than a typical essay just because of that: it was real, it was more 'out there', more interactive" (Student 1).

"We should be doing this kind of assignments [sic] more often. Because this was English, but at the same time it was computing, and research, 
and sometimes there were disagreements and we had to find a solution. And because we knew that you would be reading the change history we did everything in English, which was difficult but at the same time it was a challenge. When we were revising the contributions by the other students sometimes we couldn't explain why something was a mistake so I had to check grammar books and everything in order to make my point. And then, how do you tell them that what they wrote is not correct? I had to think of ways of letting them know without being, like, bossy" (Student 2).

\section{Discussion and conclusions}

The classroom experience presented above, in line with similar studies (Aydin \& Y1ldı, 2014; Sabet, Tahriri, \& Pasand, 2013), elaborates on the impact of asynchronous wiki-based work in the L2 classroom as a means to complement the coursework of the module. As the preliminary results of the focus group interviews attest, the positive impact students perceive in their command of their L2 through collaborative wiki-based writing is generally believed to result in higher levels of motivation when learning a foreign language, which confirms previous similar experiences by Roschelle et al. (2001), among others. At the same time, the wiki-project is believed to strengthen, in full agreement with Yang (2014), the progressive socialisation process of students in their respective discursive communities, another aspect noted consistently among the participating students.

This way, the use of wikis empowers students to create, transform, and shape their texts collaboratively in a flexible learning environment that allows the lecturer to scaffold the learning curve of their students while they work outside the classroom, supervising the project and making sure that a number of general and module-specific competences are developed. Besides, the use of wikis seems to foster further collaboration and peer scaffolding in joint processes of meaning negotiation and text production, which enhances the overall learning process of L2 learners. This, however, should be corroborated by more in-depth 
studies on the patterns and nature of collaboration (power relations within group members, etc.) and how those patterns change as the students progress and attain higher levels in their L2. The analysis of the focus group interviews seems to indicate that students tend to 'avoid' collaboration and divide texts in sections to be drafted individually, posing problems in terms of overall quality of the text, coherence, etc.

As Greenhow and Lewin (2016) suggest, there is a lack of current models that theorise social media as a space for informal learning, even if technology and social media have the potential to complement and enrich the educational picture "through greater agency, opportunities to participate in networked communities and access to a wide range of resources to support knowledge building and collaboration" (p. 6). Incorporating elements of digital pedagogy in the L2 classroom, as reflected above, may serve as a starting point for students to collaborate outside the language module, build bridges between formal, informal, and non-formal learning, and realise that foreign language education needs to be approached in a comprehensive manner. This requires both traditional, classroom-based interaction and other non-formal and informal elements that help tackle the situated, complex nature of languages, the very first and last barrier that students encounter when trying to access any foreign language.

\section{Acknowledgements}

This classroom experience was supported by a teaching innovation grant to 3470/17 Translating Wikipedia back and forth. A professional endeavour at Jaume I University.

\section{References}

Alonso, E. (2015). Analysing the use and perception of Wikipedia in the professional context of translation. The Journal of Specialised Translation, 23, 89-116. 
Aydın, Z., \& Yıldız, S. (2014). Use of wikis to promote collaborative EFL writing. Language Learning \& Technology, 18(181), 160-180.

Chun, D., Smith, B., \& Kern, R. (2016). Technology in language use, language teaching, and language learning. Modern Language Journal, 100, 64-80. https://doi.org/10.1111/ modl. 12302

Elola, I., \& Oskoz, A. (2010). Collaborative writing : fostering foreign language and writing conventions development. Language Learning \& Technology, 14(3), 51-71.

González, J., \& Wagenaar, R. (2003). Tuning. Final report. Bilbao.

Greenhow, C., \& Lewin, C. (2016). Social media and education: reconceptualizing the boundaries of formal and informal learning. Learning, Media and Technology, 4(1), 6-30. https://doi.org/10.1080/17439884.2015.1064954

Lai, K.W., Khaddage, F., \& Knezek, G. (2013). Blending student technology experiences in formal and informal learning. Journal of Computer Assisted Learning, 29(5), 414-425. https://doi.org/10.1111/jcal.12030

Lerga, M., \& Aibar, E. (2015). Best practice guide to use Wikipedia in university education.

Muñoz Raya, E. (Ed.). (2004). Libro blanco. Título de Grado de Traducción e Interpretación. Agencia Nacional de Evaluación de la Calidad y Acreditación. https://goo.gl/5FvT3W

Roschelle, J., Pea, R. D., Hoadley, C. M., Gordin, D. N., \& Means, B. (2001). Changing how and what children want to learn in school with computer-based technologies. The Future of Children, 10(2), 76-101. https://doi.org/10.2307/1602690

Sabet, M. K., Tahriri, A., \& Pasand, P. G. (2013). The impact of peer scaffolding through process approach on EFL learners' academic writing fluency. Theory and Practice in Language Studies, 3(10), 1893-1901. https://oi.org/10.4304/tpls.3.10.1893-1901

Yang, L. (2014). Examining the mediational means in collaborative writing: case studies of undergraduate ESL students in business courses. Journal of Second Language Writing, 23, 74-89. https://doi.org/10.1016/j.jslw.2014.01.003

Yim, S., \& Warschauer, M. (2017). Web-based collaborative writing in L2 contexts: methodological insights from text mining. Language Learning \& Technology, 21(1), 146165. 